\title{
Access, Aging, and Impairments Part B: Accessibility Planning
}

\author{
Jan-Dirk Schmöcker \\ Tokyo Institute of Technology a
}

Following on from Part A, "Impairments and behavioral responses," the contributions in this part of the special issue focus on the planning implications and review in how far accessibility planning has been employed in practice.

The letter by Dejeammes describes experiences with accessibility planning in French towns. It illustrates experiences and problems with the realization of a recent law that requires municipalities to improve accessibility. Though national policy might appreciate the importance of accessibility, local policy is more varied. The paper by Wennberg et al. continues to study this topic by describing the findings of a survey of Swedish municipalities aiming to understand the perception of the importance of accessibility issues as well as whether policies and guidelines are actually being implemented. The results indicate that those municipalities with higher awareness of accessibility issues also have better planning guidelines in place. The causality might, however, also be turned around-in other words, better planning guidelines help raise awareness of accessibility shortcomings.

An inherent problem of guidelines on accessibility planning is that criteria for adequate accessibility must be established in order to set investment priorities. In particular, planners need to measure the (un-)accessibility of destinations, or which population groups are especially disadvantaged. The third contribution in this special issue, by Titheridge et al., discusses how existing guidelines often fail to address the real needs of those with impairments. The paper then proposes an alternative approach tested in the UK to measure the extent of social exclusion experienced by people with mobility impairments, particularly older people.

A related problem is in the area of project evaluation. Transport planners and advocates must justify investments. The paper by Wretstrand et al. studies the mobility effects of improvements to the public transport system in Sweden and finds that there are some positive effects on older people's mobility. The question of whether the improvements reported in Sweden and found also in other places are significant enough to justify the investments is, however, difficult to answer. Wretstrand et al. conclude that more should be done to amplify the effects, as too often some parts of the journey are still not fully accessible.

The final paper, by Maynard, discusses the measurable benefits of more accessible transport with the understanding that better access to transport facilities is appreciated by a wider community than generally considered (e.g. parents with prams) and often leads to positive net present values for infrastructure improvements. Maynard argues that in project appraisals it is often forgotten that a single broken link might make the whole journey impossible- the same argument as used by Wretstrand et al. to a make a case for further investments. If one applies this argument to the two definitions of accessibility mentioned in the editorial of Part A of this special issue on "access to destinations" and "access to infrastructure," it follows that the access

${ }^{a}$ schmoecker@plan.cv.titech.ac.jp 
to a destination is only as good as the lowest level of access to any infrastructure on any path to this destination.

Indeed, one research question that might arise when reading the papers in this special issue is whether there is ever going to be "sufficient accessibility" to infrastructure and ultimately also to destinations. The social mobility of disability argument (Barnes 1991; Oliver 1990) posits that impairments only become disabilities if our society fails to accommodate people who are impaired. The questions raised by this line of enquiry-such as whether one accepts a limit to the social model of disability or ultimately demands that everything technologically possible be done to increase the accessibility of even remote or extreme locations, such as mountainous areas-are difficult to answer. Where to set such limits is an awkward question that can lead to emotional discussions.

\section{Acknowledgments}

David Levinson was of great help in the compilation this two-part special issue. Further, he and Anders Wretstrand provided valuable comments on the editorials. I would further like to thank the various reviewers who provided detailed reports on the submitted papers.

\section{References}

Barnes, C. 1991. Disabled people in Britain and discrimination: A case for anti-discrimination legislation. London: Hurst and Co.

Oliver, M. 1990. The individual and social models of disability. Paper presented at Joint Workshop of the Living Options Group and the Research Unit of the Royal College of Physicians. Available from http://www.leeds.ac.uk/disability-studies/archiveuk/Oliver/ in $\% 20$ soc\%20dis.pdf. 